\title{
Os resultados do atendimento com qualidade Disney a um grande público em evento na Pedreira Paulo Leminski (Curitiba, Paraná, Brasil)
}

\section{The results in service with Disney quality to a large audience in events at Pedreira Paulo Leminski (Curitiba, Paraná, Brazil)}

\author{
Susan Renée Klein (KLEIN, S.R.)
}

RESUMO - Este trabalho teve por objetivo analisar o diferencial de um serviço de condução de fluxo de usuários de grandes eventos, especificamente os shows, com base no atendimento de qualidade Disney. Alunos de cursos de capacitação e técnicos na área de eventos de uma instituição de ensino técnico atuaram na condução de fluxo do público em quatro shows realizados na Pedreira Paulo Leminski, sendo que o último deles reuniu um número maior de espectadores. Deste evento foram extraídas algumas respostas para um questionário orientado pela metodologia de aferição de atendimento de qualidade em serviços TOURQUAL, que poderão motivar produtores destes eventos e espaços a buscar melhorias, algumas pequenas, outras de maior atenção. Desta forma, maiores públicos poderiam vivenciar melhor cada etapa do evento, iniciando a boa experiência a partir de sua chegada.

Palavras-chave: Turismo; Eventos; Condução de fluxo; Qualidade de atendimento; Qualidade Disney.

ABSTRACT - This paper had the aim of analyzing the differential of a service of users flow conduction in big events, specifically the concerts, based on Disney quality service. Students of training courses and technicians in the events area from a technical education institution acted in the conduction of the public flow in four concerts realized in Pedreira Paulo Leminski, being the last one concert with greater number of spectators. From this event, some answers were extracted for a questionnaire guided by the methodology of quality service assessment TOURQUAL, which could motivate producers of these events and spaces to seek improvements, some small, others with greater attention. In this way, larger audiences could experience better each stage of the event, starting the good experience from their arrival on.

Key words: Tourism; Events; Flow Conduction; Service quality; Quality Disney.

\footnotetext{
* Formação: Graduação em Gestão de Vendas (Bacharelado) pelo Instituto Martinus de Educação e Cultura - PR. Especialização em Eventos Especiais pela Universidade Positivo e Curso de Extensão em Metodologia do Ensino Superior das Faculdades OPET - Curitiba-PR. Mestrado em Turismo na Universidade Federal do Paraná - UFPR. Atividade Profissional: Organizadora de eventos desde 1985. Professora do MBA de eventos na Universidade Tuiuti do Paraná e dos cursos técnico de eventos do SENAC - Serviço Nacional de Aprendizagem Comercial e da Universidade Positivo no Curso de Gestão de Eventos. E-mail: susanklein@aloeventos.com.br
} 


\section{INTRODUÇÃO}

Em tempos de instabilidade econômica, desaceleração do crescimento e modificação de hábitos para diminuição de custos, algumas mudanças no comportamento de brasileiros foram necessárias visando uma melhor aplicação de seus investimentos na área do lazer no ano de 2015. Segundo pesquisa do Portal Innovare (2016), o aumento da moeda americana elevou o custo de passagens aéreas, compras em dólar e de aquisição da própria moeda. De acordo com o Jornal Folha de São Paulo (2015), os gastos dos brasileiros com viagens internacionais caíram 25\% nos oito primeiros meses do mesmo ano.

$\mathrm{Na}$ contracorrente destas informações os investimentos feitos em viagens dentro do país em 2015 em comparação ao ano de realização da Copa do Mundo FIFA, não teve queda significativa segundo análise comparativa de dados fornecida pela ANAC (Agência Nacional de Aviação Civil) em 2015. Seguindo nesta linha, o número de eventos com grandes concentrações de públicos como o Rock In Rio 2014 recebeu 700.000 pessoas na edição do mesmo ano, ou seja, uma média de 85.000 para cada um dos 8 dias (FORBES Brasil, 2015).

A cidade de Curitiba (Paraná-Brasil) recebeu no ano de 2015 diversos shows que também reuniram grandes concentrações de públicos em dois espaços: Espaço Arena, um dos legados do evento mundial de futebol, com o show do escocês Rod Stuart, em que foram colocados à venda 35.000 ingressos (GAZETA DO POVO, 2015), e a Pedreira Paulo Leminski, que recebeu artistas de diversos gêneros musicais e também reuniu grandes volumes de públicos.

A busca por momentos de lazer de menor impacto financeiro pode ser uma alternativa para a fuga da rotina dos brasileiros, considerando que os custos são menores do que uma viagem de longas distâncias. Assistir a um show de quem se aprecia no mesmo município em que se reside ou próximo, pode levar o usuário a viver uma experiência única, porém em período menor do que em uma viagem de lazer, ou seja: participar de um evento.

Por sua vez, um conceito básico associado concernente a um evento é o de que seja um: 
[...] acontecimento que ocorre a partir de um motivo e de atividades programadas a serem desenvolvidas em um local e tempo determinados, congregando indivíduos com interesses e objetivos comuns, de mobilização da cadeia produtiva e de serviços públicos de uma localidade (BAHL, 2003, p. 18),

A partir dessa definição se pode enfatizar a necessidade de compreensão sobre a variedade de motivações, interesses e objetivos inerentes a um evento, atividades a desenvolver, bem como quanto ao grau de envolvimento de empresários da iniciativa privada e gestores de entidades públicas quando da sua realização.

Por exemplo, empresas com negócios voltados ao lazer e entretenimento passaram a aproveitar a mudança no consumo dos brasileiros e oferecer mais opções de menor impacto em espaços consagrados ou alternativos para promover a experiência de conquista de um sonho. Com uma visão de tratar os públicos de maneira mais acolhedora e realizar os atendimentos de qualidade, a possibilidade de se atrair e reter mais públicos em outros eventos pode ser maior.

No presente artigo pretendeu-se demonstrar os resultados de um trabalho realizado por uma equipe de 60 alunos de diversos cursos técnicos e de capacitação na área de eventos que receberam um treinamento básico de atendimento com qualidade Disney e exerceram a condução e orientação do fluxo dos usuários de um show realizado em 14 de dezembro de 2015 na Pedreira Paulo Leminski em Curitiba.

O trabalho já havia sido feito em três eventos anteriores no mesmo espaço, porém não aferido com questionário ou entrevistas. O que se havia percebido é que a dinâmica da condução de fluxo acelerava a entrada de grandes públicos.

Que com o resultado avaliado neste evento através das entrevistas, questionários e análise pela ferramenta TOURQUAL, possa surgir uma motivação maior voltada ao bom tratamento dos futuros e habituais frequentadores de eventos realizados tanto na Pedreira Paulo Leminski quanto em outros espaços com a mesma proposta.

\section{REVISÃO DA LITERATURA}

Os encontros entre tribos ou a automotivação para decidir assistir a um espetáculo podem ser explicados com a teoria do triunfo do espetáculo de Guy Debord (1967) amplamente discutido no artigo de Douglas Kellner para a Revista Líbero (2004). 
Se uma compra pode ser motivada pelo desejo de viver uma experiência única, baseada em vivências ou fantasias será um dos fatores a ser considerado para a compreensão desta forma de consumo (JAFARI, 2010; HOLBROOK; HIRSCHMANN, 1982; TEARE, 1998).

A experiência a ser vivida, pode ser ampliada se o usuário da experiência for conduzido adequadamente ao espaço, sentir-se parte do cenário e da cena realizada (DONNELLEY, 2011).

Dados e fatos podem comprovar uma modificação nos interesses de usuários, ou convidados, como as empresas da Disney preferem nominar, voltados para a experiência única ou inédita (FOLHA DE SÃO PAULO, 2015; GAZETA DO POVO, 2015; PREFEITURA DE CURITIBA, 2015; ANAC, 2015).

Considera-se que uma pesquisa realizada, com posterior análise da ferramenta TOURQUAL, entre usuários de um evento realizado na Pedreira Paulo Leminski, que lotou a sua capacidade de 30.000 pessoas poderá estimular este espaço e demais com a mesma vocação a compreender de maneira quantitativa e qualitativa a responsabilidade de se promover estes eventos e ampliar em número e qualidade os usuários de intervenções futuras.

\section{QUALIDADE DE ATENDIMENTO NO TURISMO}

Segundo Teare (1998, p. 101) o atendimento de qualidade passa por um processo que envolve os setores internos da empresa prestadora de modo integrado e em um formato espiralado se conecta com os setores externos à corporação, lembrando um DNA. A relação entre todos os setores internos envolvendo a base e os altos cargos precisa ser transparente, clara e conectada às etapas da comercialização. Resumidamente ela se inicia na pré-venda, passa pela conquista, a venda, o pós-venda e a retenção do cliente uma vez que a manutenção constante dos produtos ou serviços adquiridos deve acontecer com um potencial esforço nesta etapa. Gráficos demonstrando a forma de relação sugerida por Teare (1998, p. 103) entre os setores internos da empresa prestadora e a forma como cada um deles pode participar do processo já descrito, facilitam e motivam os integrantes a envolver-se com a missão de conquistar e reter clientes. 
Para uma melhor compreensão sobre a importância dada atualmente ao capital social ou humano, Jafari (2010, p. 13) menciona que no século 19 os economistas clássicos identificavam três fontes de riqueza conhecida: a terra, o trabalho e o capital. Nas últimas décadas do século 20, porém, governos e instituições públicas e privadas perceberam que o investimento feito em educação, cultura e outros voltados ao capital humano ou institucional não mais foram vistos como despesas.

O capital social passou a ser visto como a base de sustento das instituições. Segundo o mesmo autor, a promoção da evolução de cada indivíduo desde a mudança de ambientes comerciais e industriais até a valorização de necessidades pessoais ganhou nova importância. O indivíduo passou a ser valorizado por sua educação e formação, que até hoje é quase impossível sem o apoio das instituições. Da mesma forma, também é valorizada a produção continuada de conhecimento e pesquisa e suas aplicações para melhorar a vida da sociedade: Inovação (JAFARI, 2010, p. 14).

O sistema de resposta do consumidor com base no conhecimento, afeto e comportamento, defendido por Holbroock e Hirschman (1982), descreve para estes três pilares resumidamente o seguinte:

\subsection{CONHECIMENTO}

Para este primeiro pilar, o processamento de informações orientadas ao conhecimento ou ao cognitivo baseia-se na memória e em fenômenos já vivenciados e guardados no inconsciente bem como as perspectivas experienciais que podem envolver fantasias e devaneios. A resposta do consumo, na área do conhecimento, é defendida pelo uso e aplicação de pesquisas para formulação de hipóteses que definam melhor o que de fato é desejo e ou necessidade na elaboração de novos produtos ou serviços.

\subsection{AFETO}

Segundo os autores, o processamento da informação enfatiza apenas o aspecto da hedônica, ou seja, o consumidor pode gostar ou não de uma marca, atitude, espaço, serviço ou situação. Este pilar está baseado, portanto em emoções e sentimentos como amor, ódio, medo, alegria, tédio, ansiedade, orgulho, raiva, nojo, tristeza, simpatia 
luxúria, êxtase, a ganância, a culpa, exaltação, vergonha e temor. Valorizar este aspecto na elaboração de produtos e serviços de lazer, entendendo que as emoções fazem parte do substrato do consumo pode ser requisito para o seu sucesso.

\subsection{COMPORTAMENTO}

Pesquisas do passado demonstravam apenas o processo de escolha de um item sobre outro. Nos últimos 60 anos, porém estabeleceu-se uma diferença entre comprar e consumir. Neste sentido o que chama a atenção dos autores é a experiência que se adquire com o produto ou serviço a ser consumido. Com esta informação, sem muito aprofundamento, vale entender que:

[...] a importância de tal estudo é reforçada pela ênfase no entretenimento, artes e lazer relacionados com ofertas, que muitas vezes dependem mais do tempo do que do dinheiro... a operação do princípio do prazer na gratificação multissensorial, fantasias excitantes, e as emoções características que levam à decisão de compra são apenas um componente na constelação dos eventos que envolvem experiência do consumo (HOLBROOCK; HIRSCHMAN, 1982, p. 135).

Sem muito se detalhar ou aprofundar sobre este rico tema, que não é objetivo central deste trabalho, um autor mencionado tanto por Hollbrook e Hirschman, como por grande parte dos que estudam fenomenologia e Behaviorismo, MacLeod (1964, p. 51) é citado para ilustrar os mecanismos de decisão no processo de compra:

[...] Cores e sons são dados/informações; assim também as impressões de distância e duração; da mesma forma são os sentimentos de atração e repulsão; os anseios e medos, êxtases e desilusões; assim como todas as relações que variam do desconhecido e óbvio para o delicado e intangível, esta é a forma de desejo que o mundo nos apresenta.

Empresas de qualquer área que estejam atentas a estes conceitos ou pensamentos que não são novos, mas comprovadamente, como se verá no próximo tópico, eficazes têm maiores chances de se tornarem competitivas pelo aspecto da valorização de seus consumidores, usuários ou clientes. 


\section{ATENDIMENTO NO TURISMO COM A QUALIDADE DISNEY}

Muito se lê e já se escreveu a respeito de qualidade no atendimento na área do turismo. Mas um fato que não pode se ocultar é que Walt Disney, desde o seu primeiro empreendimento em 1955 já impôs a qualidade nos serviços como ponto central de sua preocupação. Afirmar que criou um conjunto de empresas que alcançou o sucesso em função desta tônica é redundante uma vez que no inventário integrante do relatório aos acionistas de 1999 a Walt Disney Company já apresentava:

[...] sete parques temáticos (e quatro em construção), 27 hotéis com 36.888 quartos, dois navios de cruzeiro, 728 lojas, uma rede de rádio e televisão, dez emissoras de TV, nove canais internacionais, 42 estações de rádio, um portal de internet, cinco grandes sites, além de nos anos 1990, a Disney ter ampliado sua coleção com 17 animações, 265 filmes e 1.252 episódios animados e 6.505 episódios liveaction (com atores) de TV. (DONNELLEY, 2011, p. 16).

Tanto a qualidade no atendimento das empresas com a marca Disney inspirou outras empresas de setores muito distintos que foi criado em 1974 o Disney Institute para ensinar sobre o assunto. Hospitais, indústria automobilística, farmacêutica, cosmética, empresas prestadoras de serviço como seguradoras, bancos, internet, buscam aperfeiçoar os seus atendimentos através e cursos ministrados pelo Disney Institute.

Um dos pontos iniciais é a apresentação do ciclo de atendimento de qualidade visto como uma espiral contínua com os clientes, ou como conhecidos na nomenclatura própria, os convidados, no centro. Este ciclo trata do atendimento, elenco, cenário, processo e a integração de cada um deles (DISNEY INSTITUTE, 2016). Visando alcançar os objetivos do presente artigo, os cinco itens do ciclo serão apresentados a seguir:

\subsection{ATENDIMENTO OU A MAGIA DO ATENDIMENTO}

Segundo Donnelley (2011), para Disney o ciclo do atendimento inicia-se "no centro do circuito, com as necessidades, desejos, percepções e emoções dos convidados".

Do neologismo da palavra em inglês para convidado, guest, foi criada a ciência de conhecer e entender o cliente, ou "guestologia". O ciclo de atendimento de qualidade 
está centrado no atendimento de uma organização. Para a Disney o tema, ou força propulsora do atendimento é: "Criar felicidade para pessoas de todas as idades, por toda parte.” (DONNELLEY, 2011, p. 28).

De acordo com o mesmo autor, o tema pode alinhar as ações dos membros do elenco e estabelecer as bases para seu comportamento em relação aos seus públicos, estabelecendo os critérios para as ações necessárias e concretizá-lo, servindo como medida para o atendimento de qualidade. Os padrões de atendimento por ordem de importância são: segurança, cortesia, espetáculo e eficiência.

\subsection{A MAGIA DO ELENCO}

Como já mencionado em tópico anterior, as organizações passaram a perceber que os ativos mais importantes das empresas são os funcionários. Falar de atendimento de qualidade sem que exista a interface de um funcionário é impossível, ao menos por enquanto. Michel Eisner (1999, p. 228) escreveu que "nada define com tanta visibilidade os parques da Disney como a cordialidade e o comportamento dos membros do elenco ao longo dos anos e a apreciação que os convidados sentem pelo modo como são tratados".

\footnotetext{
Vale reforçar que os parques temáticos da Disney mensuram o impacto do elenco sobre a experiência do convidado há mais de 40 anos. Qual é um dos motivos mais frequentes que levam os convidados a voltarem para outra visita? O elenco (DONNELLEY, 2011, p. 29).
}

Os funcionários, ou elenco como são nominados, exercem um grande número de papéis. Segundo Donnelley (2011, p. 29), o elenco é preparado de acordo com uma cultura de apresentação do conjunto de comportamentos, trejeitos, termos e valores sempre que se integram a cada local de trabalho.

\subsection{A MAGIA DO CENÁRIO}

O cenário refere-se, na linguagem da Disney, ao espaço em que os clientes estão, desde a chegada, a utilização de serviços e atrações, o descanso, o consumo de alimentos e bebidas. "A importância de gerenciar o efeito do cenário sobre a experiência do convidado pode ser resumida em três palavras: Tudo faz diferença” (DONNELLEY, 2011, p. 30). 
No Walt Disney Resort, esta expressão, segundo o autor significa que os detalhes desde uma maçaneta até a sala de jantar transmitem uma mensagem aos convidados. Em qualquer circunstância, nesta teoria, a mensagem transmitida pelo cenário, deve ser coerente com os padrões de atendimento, além de sustentar e estender o espetáculo que estiver sendo criado. "Quando os componentes do cenário são utilizados para instruir os clientes, dizemos que eles orientam a experiência do convidado" (DONNELLEY, 2011, p. 104).

\subsection{A MAGIA DO PROCESSO}

No Walt Disney World, os processos de atendimento, incluem conduzir os convidados pelas atrações, os serviços, bem como em situações de emergência como problemas médicos e incêndios ou acidentes. Cada processo tem pontos de combustão, ou pontos de possível falha, que podem tornar a experiência do convidado ruim (DONNELLEY, 2011, p. 31). Todo o treinamento do elenco para estas situações visa que estes pontos não se tornem pontos de explosão. Criar soluções ou ajustes a partir de situações inusitadas pode ser a receita para o sucesso no processo de atendimento.

Para Disney, o processo no parque de diversões, um processo precisa ser repetido continuamente e resultar no mesmo produto a cada vez: entretenimento, experiência e realização (DONNELLEY, 2011, p. 122).

\subsection{A MAGIA DA INTEGRAÇÃO}

A integração é um processo lógico, passo a passo, regido por uma matriz, também mencionada por Teare (1998, p. 103). De acordo com Denneley (2011, p. 32):

[...] elenco, cenário e processo se fundem na busca do tema e dos padrões de atendimento resultando em uma experiência de qualidade excepcionalmente alta para o convidado, o que impulsiona o sucesso de todas as organizações conhecidas pela excelência em serviços.

A matriz que o atendimento de qualidade Disney apresenta, relaciona os quatro padrões de atendimento já mencionados na ordem de importância: segurança, cortesia, espetáculo e eficiência aos três elementos fundamentais e responsáveis para este atendimento, ou seja: elenco, cenário e processo (DONNELLEY, 2011, p. 56). 


\section{PEDREIRA PAULO LEMINSKI}

A Pedreira Paulo Leminski faz parte do Parque das Pedreiras, área de 103.500 $\mathrm{m}^{2}$, em Curitiba, no espaço em que funcionava a Pedreira Municipal e uma usina de asfalto, implantada em 1990 e que compõem com a Ópera de Arame um espaço estruturado para receber os mais variados públicos de turismo de lazer e de eventos (PREFEITURA DE CURITIBA, 2015).

Sua capacidade de público é de 30.000 pessoas. Foi reinaugurado em março de 2014 depois de uma reforma, realizada por uma empresa privada comodatária, em que recebeu saídas de emergência, a remodelação da área do palco de $480 \mathrm{~m}^{2}$ e pista exclusiva para portadores de necessidades especiais (PREFEITURA DE CURITIBA, 2015). Naquele ano foi palco de festivais ${ }^{1}$, shows nacionais ${ }^{2}$ e também do evento Fifa Fan Fest (PORTAL G1, 2014).

No ano de 2015, recebeu eventos de médio porte, para até 2.000 pessoas, na área da gastronomia, e de grande porte, para públicos superiores a 10.000 pessoas como festivais de música eletrônica (Warung Day Festival), sertaneja (Country Festival), pop (Estação Pedreira), além de shows de artistas internacionais como Kiss, Monster's Tour (Ozzy Osbourne, Motorhead e Judas Priest), Katy Perry e David Gilmour.

Cada evento, dependendo de sua necessidade, é construído em formatos específicos visando atender às demandas e necessidades de seus usuários. O fato de ter sido concebida para eventos (sem precisar de adaptações como proteção de gramado, por exemplo), evidencia esta facilidade de montagens diferenciadas.

No mesmo sentido em que os eventos para médios e grandes públicos aconteceram neste espaço em 2015, houve um aumento do pagamento de impostos sobre serviços não vinculados à saúde ou educação no município de Curitiba. O quadro 1 a seguir visa demonstrar a arrecadação nos meses de setembro e dezembro de 2014 e 2015 respectivamente:

\footnotetext{
${ }^{1}$ Festivais realizados na Pedreira Paulo Leminski em 2014: Warung Day Festival e Estação Pedreira.

${ }^{2}$ Shows nacionais realizados na Pedreira Paulo Leminski em 2014: Roberto Carlos (Reinauguração do espaço) e Raimundos.
} 


\begin{tabular}{|l|l|l|l|}
\hline \multicolumn{1}{|c|}{ Mês/Exercício } & \multicolumn{1}{|c|}{2014} & 2015 & Diferença \\
\hline Set & $\mathrm{R} \$ 38.978 .983,44$ & $\mathrm{R} \$ 53.014 .855,28$ & $26 \%$ \\
\hline Dez & $\mathrm{R} \$ 33.483 .101,36$ & $\mathrm{R} \$ 71.483 .278,38$ & $53 \%$ \\
\hline
\end{tabular}

QUADRO 1 - DIFERENÇA DE ARRECADAÇÃO DE ISS DE SETEMBRO E DEZEMBRO DE 2014 E 2015 - PREFEITURA DE CURITIBA

FONTE: Elaborado pela autora a partir do Portal da Transparência Curitiba-PR, 2016.

Os períodos analisados em 2015 foram os meses em que aconteceram os shows de Katy Perry (setembro) e David Gilmour (dezembro), que, quando comparado ao mesmo período do ano anterior demonstraram um aumento de $26 \%$ e de $53 \%$ respectivamente na arrecadação.

\section{A EXPERIÊNCIA DA CONDUÇÃO DE FLUXO DO ATENDIMENTO DE QUALIDADE DISNEY}

Lecionando para cursos de eventos do Serviço Nacional de Aprendizagem Comercial - SENAC, um dos autores deste artigo foi ministrante da disciplina de prática profissional que tem a carga de 136 horas. Entendendo que esta prática seria mais bem reforçada se os alunos tivessem experiências reais em eventos de naturezas diversas, buscou parceria com algumas empresas voltadas à elaboração ou produções locais de eventos de grandes públicos.

Por ocasião de um festival de música sertaneja, foi realizado em parceria com a empresa idealizadora do evento, um treinamento com base no atendimento de qualidade Disney aos alunos dos cursos técnicos e de capacitação de eventos da instituição. Foram apresentados os cinco pilares já mencionados sendo que a maior ênfase se deu sobre o elenco e o processo. A ênfase do trabalho seria a condução do fluxo dos usuários, ou convidados, como Disney prefere nominar, desde o início das ruas de acesso ao espaço, até a sua chegada ao espaço do evento adquirido.

Três eventos ${ }^{3}$ aconteceram com mais ou menos alunos, em função de concluírem a sua formação em etapas distintas, até o maior deles em termos de capacidade de público, em que uma pesquisa foi aplicada para a aferição do resultado deste tipo de trabalho: David Gilmour, ex-guitarrista da Banda Pink Floyd, em 14 de dezembro de 2015.

\footnotetext{
${ }^{3}$ Monsters Tour (Ozzy Osbourne, Mötorhead e Judas Priest) foi realizado em 28/04/2015; Country Festival em 23/05/2015 e Katy Perry em 29/09/2015 (Portal G1 - Agenda de Shows, 2015).
} 
Com a experiência dos três eventos anteriores em que puderam ser verificados públicos diferentes em gosto, estilo e comportamentos, o evento mencionado aguardava a chegada de um público muito numeroso, com características que a pesquisa realizada poderá apontar.

O processo de condução de fluxo realizado pelos alunos do SENAC teve dois lados a ser valorizados. Primeiro, a experiência proporcionada ao estudante que busca formação na área de eventos, de atuar em um evento de maior porte. Segundo, aos usuários do espaço, que inesperadamente foram educadamente abordados e orientados sobre a direção em que deveriam seguir, de acordo com o tipo de ingresso, sobre consumo de alimentos e bebidas, que objetos não seriam aceitos na revista feita pelas equipes de segurança e a necessidade de portarem documentos pessoais para a passagem pelas catracas.

\section{METODOLOGIA}

Os dados primários para a pesquisa foram coletados através de um questionário elaborado para avaliar a percepção da qualidade de atendimento aos usuários do espaço Pedreira Paulo Leminski nas várias etapas de sua experiência, desde a chegada aos arredores do espaço, a entrada, o período de permanência no espaço com utilização de serviços até a saída. O modelo de mensuração TOURQUAL ${ }^{4}$ foi elaborado para a avaliação da qualidade de serviços em atrativos turísticos (MONDO, T. S., 2014). Este modelo foi adotado, pois se aproximou mais dos objetivos de avaliação dos resultados deste tipo de serviços.

Foram realizadas duas entrevistas sendo uma com um dos patrocinadores da equipe de condução de fluxo e outra com o representante de um grupo, ou tribo, que frequentou o evento em questão.

\footnotetext{
${ }^{4}$ TOURQUAL: Ferramenta de aferição da qualidade de serviços da área turística dividida em categorias e indicadores (MONDO, T. S. 2014).
} 


\title{
8 ENTREVISTAS, PESQUISA E ANÁLISE TOURQUAL
}

Para viabilização do trabalho $^{5}$ de condução de fluxo, a pesquisadora por iniciativa própria, buscou exercer uma maior valorização do elenco, alcançando patrocínio financeiro para poder pagar um cachê, realizar o serviço de alimentação adequado considerando que a carga de trabalho foi superior a onze horas, hidratação com água e isotônicos e um presente especial para o elenco. Três empresas foram simpatizantes deste tipo de trabalho sendo que duas apoiaram financeiramente e uma com brindes e protetor solar aos usuários do evento ${ }^{6}$.

Foram realizadas duas entrevistas, ao patrocinador e representante de um grupo de usuários/convidados e a pesquisa por questionário dirigido.

\subsection{ENTREVISTA COM O PATROCINADOR}

Realizada com uma das empresas apoiadoras da equipe de condução de fluxo, foram feitas e respondidas as seguintes perguntas à responsável pela área comercial por meio eletrônico:

1) $\mathrm{O}$ que motivou o patrocinador a apoiar a equipe que realizou o trabalho de condução de fluxo?

Resposta: "Nosso interesse foi que o público deste show ou fala a língua inglesa ou está aprendendo ou ainda tem muito interesse em iniciar os estudos”.

2) Houve retorno percebido por parte de seu público interno, quando soube de tal iniciativa?

Resposta:

\begin{abstract}
Nós sorteamos os acessos que fizeram parte da contrapartida de nosso patrocínio. Quando os funcionários souberam do sorteio ficaram animados inclusive em frequentar a festa de fim de ano, não tão valorizada em anos anteriores. Os funcionários sorteados com o ingresso ficaram muito felizes e agradeceram bastante.
\end{abstract}

\footnotetext{
${ }^{5}$ Nos eventos mencionados não houve o reconhecimento financeiro e o serviço de alimentação foi restrito a um sanduiche e com escassez de água para o período.

${ }^{6} \mathrm{O}$ horário de abertura dos portões se deu às 15:00 horas e o sol batendo de frente para quem chegava ao espaço. No show anterior a pesquisadora observou este fenômeno e buscou o patrocínio de protetores solares.
} 
3) Sobre a campanha midiática realizada pela empresa, houve retorno para o patrocinador? Que tipo de retorno foi percebido?

Resposta: "A distribuição de flyers do fim do show teve certo resultado. Poucos flyers no chão, o que significa que não foram desperdiçados e eu mesma atendi alguns interessados em conhecer nossos serviços, em virtude do material recebido no evento".

Em conclusão, verificou-se que o patrocínio da equipe de condução de fluxo modificou o comportamento do público interno da empresa apoiadora e trouxe visibilidade vinda do público externo abordado pelo material de divulgação.

\subsection{ENTREVISTA COM UM REPRESENTANTE DE UM GRUPO DE CONVIDADOS}

O resultado da entrevista realizada por telefone, com um representante de um grupo de amigos que frequentavam juntos alguns shows, deste evento foi a seguinte:

1) Quais foram as suas expectativas sobre o show em questão?

Resposta:

De que haveria muita gente (acima do que vivenciamos em show do Iron Maiden de 2013 no mesmo espaço), e que, portanto entraríamos com atraso por ficar muito tempo na fila (mais do que no show anterior). Expectativas positivas foram de que haveria qualidade sonora e conforto, já que investimos em ingressos mais onerosos.

2) Estas expectativas foram supridas? De que forma?

Resposta: "Sim. O evento iniciou no horário, não nos incomodamos com o espaço, tivemos conforto, apesar do grande número de espectadores e a qualidade sonora foi excelente".

3) Houve uma percepção sobre o trabalho de condução de fluxo realizado nos arredores da Pedreira Paulo Leminski? Este trabalho fez diferença na sua experiência?

Resposta: A impressão que tivemos foi de que a nossa entrada havia sido planejada. Do
momento em que chegamos, 2 horas antes do início do show, até estarmos na
área da plateia, levamos 10 minutos. A agilidade neste processo de orientação
foi dinâmica e fez toda a diferença. No evento passado, do Iron Maiden
$24 / 09 / 2013$, levamos mais de 2 horas na fila, sendo que chegamos no mesmo
horário. Se aquele evento tivesse começado no mesmo horário do David
Gilmour, teríamos perdido 30 minutos do início. 
Concluiu-se que o grupo de espectadores ou convidados representado por este entrevistado conseguiu perceber a diferença que a equipe de condução de fluxo proporcionou uma vez que acessaram o seu espaço em um tempo muito menor em comparação ao evento que o mesmo grupo havia frequentado dois anos antes.

\subsection{PESQUISA ORIENTADA TOURQUAL}

De acordo com Leal (2011), a pesquisa em turismo no Brasil foi modificada depois dos anos 1990. Depois desta década, a repetição de ideias, conceitos e metodologias, alcançaram maiores resultados na produção (venda) e conhecimento científico na área do turismo. Assim, metodologias e ferramentas de apoio a pesquisa surgiram para que houvesse um resultado mais qualitativo.

No tocante ao presente trabalho, a pesquisa ou coleta dos dados foi realizada pelos integrantes da equipe de condução de fluxo, por meio de um questionário sugerido pelo criador da ferramenta (vide apêndice I), Professor Dr. Tiago Savi Mondo, em que as cinco primeiras perguntas são indicadores sobre o elemento humano $(\mathrm{EH})$ e as demais categorias do próprio TOURQUAL e que, portanto analisam acesso (ACESSO), qualidade técnica (QT), experiência (EXP) e conforto (CONF) dos usuários.

Após a compilação dos 350 questionários aproveitados, uma matriz para a análise apresentada no quadro a seguir foi gerada em que se podem verificar os quantitativos de cada indicador (vide apêndice II).

Os alunos que atuaram na condução de fluxo dos usuários do evento circularam na área interna do espaço antes do horário de início do show, no intervalo e também na saída e entrevistaram alguns dos usuários. Após eliminação de cerca de 10 questionários não respondidos por completo, a amostra aproveitada foi de 350 respondentes.

Foram elaborados índices de qualidade de cada indicador e das categorias. As cores também foram utilizadas para uma separação visual de áreas dos índices em críticos (vermelho), que merecem atenção (amarelo) e os que estão bons (verdes).

O quadro 2 a seguir apresenta o resultado desta pesquisa já com a separação dos índices por cor e as perguntas respondidas com índices de satisfação. 


\begin{tabular}{|c|c|c|}
\hline CATEGORIA & INDICADOR & $\begin{array}{c}\text { INDICE DE } \\
\text { QUALIDADE }\end{array}$ \\
\hline $\mathrm{EH}$ & Prestação de informações na entrada do evento & 4,81142857 \\
\hline $\mathrm{EH}$ & Atenção dispensada pela pessoa que lhe atendeu & 4,72285714 \\
\hline $\mathrm{EH}$ & Conhecimento técnico da pessoa que lhe atendeu & 4,68285714 \\
\hline EXP & Nível de fuga da rotina & 4,67428571 \\
\hline EH & Confiança depositada na pessoa que lhe atendeu & 4,57428571 \\
\hline EXP & Diversão no evento & 4,46857143 \\
\hline $\mathrm{EH}$ & Atendimento Geral no Evento & 4,46571429 \\
\hline QT & Variedade de Atividades oferecidas no evento & 4,40571429 \\
\hline CONF & Som e acústica do evento & 4,39142857 \\
\hline EXP & Nível de aprendizado no evento & 4,32857143 \\
\hline QT & Condições climáticas do evento & 4,29142857 \\
\hline ACESSO & Horário de Funcionamento do Evento & 4,24571429 \\
\hline QT & Infraestrutura no evento & 3,14285714 \\
\hline CONF & Conforto no evento & 3,12285714 \\
\hline QT & Oferta de tecnologia no evento & 2,89714286 \\
\hline SEG & Segurança percebida & 2,86285714 \\
\hline QT & Sinalização interna no evento & 2,81428571 \\
\hline EXP & Beleza no evento & 2,7 \\
\hline QT & Limpeza no Evento & 2,47428571 \\
\hline QT & Níveis de preço cobrados & 2,36285714 \\
\hline ACESSO & Banheiros (disponibilidade, acesso e limpeza) & 2,28 \\
\hline ACESSO & Filas no Evento & 1,76285714 \\
\hline QT & Quantidade de pessoas no evento & 1,62571429 \\
\hline ACESSO & Localização, acesso e estacionamento & 1 \\
\hline
\end{tabular}

QUADRO 2 - CATEGORIAS E INDICADORES PARA ÍNDICES DE QUALIDADE SHOW DAVID GILMOUR 14/12/2015

FONTE: TOURQUAL (2016) a partir da compilação dos 350 questionários.

O quadro 3 apresenta a média das cinco categorias analisadas com índices satisfatórios para elemento humano e experiência, que merecem atenção, conforto e qualidade e que estão críticos na área da segurança e acesso.

\begin{tabular}{|l|l|}
\hline MÉDIA DAS CATEGORIAS & \\
\hline ELEMENTO HUMANO & 4,651429 \\
\hline EXPERIÊNCIA & 4,042857 \\
\hline CONFORTO & 3,757143 \\
\hline QUALIDADE TÉCNICA & 3,001786 \\
\hline SEGURANÇA & 2,862857 \\
\hline ACESSO & 2,322143 \\
\hline
\end{tabular}

QUADRO 3 - MÉDIA DOS ÍNDICES PARA AS CINCO CATEGORIAS FONTE: TOURQUAL (2016). 
A análise dos Quadros 2 e 3 mostra que os indicadores voltados para o elemento humano, ou seja, prestação de informações na entrada do evento, atenção e conhecimento e confiança da pessoa que fez o atendimento bem como o atendimento geral do evento foram os mais bem conceituados. Os indicadores voltados para a experiência, portanto nível de fuga da rotina, diversão e aprendizado foram também elevados. Nesta categoria, um dos indicadores merecedor de atenção especial por parte dos produtores nos próximos eventos é o da beleza no evento.

Segundo Donnelley (2011, p. 36), os clientes ou usuários são os "juízes mais importantes - e finais - do entretenimento produzido". Na área da guestologia (termo utilizado por Disney para pesquisa de mercado e cliente), existe uma verba aplicada para um grande número de técnicas como espaços para responder perguntas dos convidados, solucionar problemas e coletar informações. Os estudos e pesquisas nesta área preparam melhor o elenco e o cenário para uma maior integração com o convidado. Vale mencionar uma frase de Walt Disney para a análise destas categorias: "Você não constrói nada sozinho. Você descobre o que as pessoas querem e constrói para elas.”(DONNELLEY, 2011, p. 40).

Para conhecer e entender os convidados, a guestologia se utiliza de dois fatores: os demográficos e os psicográficos. Os fatores demográficos informam quem são os clientes, atributos físicos e procedências. Para a pesquisa realizada foram coletadas algumas informações apresentadas no quadro 4 a seguir:

\begin{tabular}{|c|c|c|c|c|}
\hline \multirow{2}{*}{ Estado de Origem } & Paraná & Santa Catarina & São Paulo & Brasília-DF \\
\cline { 2 - 5 } & 237 & 68 & 18 & 15 \\
\hline \multirow{2}{*}{ Gênero } & Feminino & Masculino & ------- & ------ \\
\hline \multirow{2}{*}{ Idade } & 125 & 225 & ------ & $41-50$ \\
\hline \multirow{2}{*}{ Estado Civil } & $16-20$ & $21-30$ & $31-40$ & 199 \\
\cline { 2 - 5 } & 35 & 39 & 77 & Viúvo \\
\hline \multirow{2}{*}{$\begin{array}{c}\text { Srau de } \\
\text { Escolaridade }\end{array}$} & $\begin{array}{c}\text { Ensinorciado } \\
\text { Fundamental }\end{array}$ & Ensino Médio & Ensino Superior & Pós-Graduação \\
\cline { 2 - 5 } & 10 & 12 & 220 & 108 \\
\hline
\end{tabular}

QUADRO 4 - PERFIL DOS USUÁRIOS OU CONVIDADOS NO EVENTO DE 14/12/2015 NA PEDREIRA PAULO LEMINSKI.

Fonte: Elaborado a partir do questionário TOURQUAL aplicado. 
Nota-se pela análise que o público foi em sua maioria masculino, com idade entre 41 e 50 anos, casado e de nível superior.

Segundo Donnelley (2011, p. 42), os fatores psicográficos oferecem indicativos sobre os que os clientes precisam, o que querem, quais noções preconcebidas trazem consigo e quais emoções vivenciam, e que no Instituto Disney também recebem indicadores para as categorias analisadas, e que se aproximam do conceito do sistema de resposta do consumidor com base no afeto de Holbroock e Hirschman (1982).

Vale, portanto analisar as categorias do TOURQUAL relacionadas ao conforto dos convidados que foram classificados satisfatoriamente no indicativo som e acústica do evento e com a atenção a ser dada no indicativo conforto do evento. Para este fator psicográfico é importante avaliar as categorias que não receberam uma boa conceituação voltada à segurança e ao acesso dos usuários ou convidados aos banheiros, área de estacionamento e tempo de espera na fila.

\section{CONSIDERAÇÕES FINAIS}

A qualidade no atendimento é amplamente discutida em diversos níveis comerciais e industriais, de produtos ou serviços. Aproveitar todo o legado oferecido pelo Disney Institute pode ser um encurtamento do processo: tentativa e erro de produtores de espetáculos e dos espaços de eventos.

Com base no pressuposto de que a filosofia Walt Disney é um modelo de excelência em qualidade de atendimento (podendo ser objeto de novas pesquisas sobre o tema), levou-se em consideração o fato da experiência turística, evidenciando os eventos, proporcionar subsídios de vivência com base no imaginário individual ou coletivo, necessitando de um receptivo preparado para bem-receber o turista/visitante.

Por fim, o resultado da pesquisa desenvolvida com a ferramenta TOURQUAL mostrou índices satisfatórios muito bem avaliados (vide apêndice 2) que podem ser aproveitados para a divulgação e comunicação de futuros eventos. Um dos indicadores que se refere à equipe de condução de fluxo, que foi avaliado de modo muito satisfatório por parte dos respondentes é o que ficou evidenciado na pesquisa. 
Os indicadores que mereceram atenção, ou críticos, são pontos que podem ser aproveitados pelos espaços ou produtores de eventos, e que precisam ser melhorados para alcançar níveis de satisfação superiores. Se a pergunta fosse, quem ganha com isso considera-se poder responder que Todos: Plateia, espaços de eventos, trabalhadores ou elenco e artista. No momento de tantas mudanças e adaptações para a área de realização de sonhos, por que não?

Considera-se, diante do estudo realizado, que a receptividade e a qualidade no atendimento durante o evento de apresentação de David Gilmour foi muito satisfatória e que a equipe condutora estava preparada, qualificada e disposta para bem-atender o público durante a realização do show. Aproveitar o resultado deste estudo em eventos futuros, agregando valor à experiência dos convidados dos próximos eventos pode ser o caminho para a concretização de uma agenda de eventos culturais e de entretenimento ainda mais consolidada.

\section{REFERÊNCIAS}

ANAC. Demanda e oferta do transporte aéreo (28/12/2015). Disponível em: $<$ http://www2.anac.gov.br/estatistica/demandaeoferta/DemandaeOferta.asp>. Acesso em: 22/1/2016.

BAHL, M. Turismo e Eventos. Curitiba 1. Ed. 2004

DISNEY INSTITUTE. Disponível em: <https://disneyinstitute.com>. Acesso em: 21/1/2016.

DONNELLEY, R. R. - O jeito Disney de encantar os clientes. São Paulo 1. ed. $14^{\mathrm{a}}$ tiragem, p. 16, 27-32, 40-42, 104, 122, 165.

EISNER, M.D. Work in progress: risking failure surviving success 1999, p. 228. New York, Random House

FOLHA DE SÃO PAULO. Gasto com viagens internacionais apresenta queda de $46 \%$ em agosto - Fábio Monteiro - 20/09/2015. Disponível em: <http://www1.folha.uol.com.br/mercado/2015/09/1684841-gasto-com-viagensinternacionais-apresenta-queda-de-4625-em-agosto.shtml>. Acesso em: 21/1/2016.

FORBES BRASIL, Os maiores públicos da história do Rock in Rio. Disponível em: $<$ http://www.forbes.com.br/listas/2017/09/os-maiores-publicos-da-historia-do-rock-inrio-2017/>. Acesso em: 10/10/2017. 
HOLBROOK, K. B.; HIRSCHMAN, E. C. The experiencial aspects of consumption: consumer fantasies, feelings and fun. Journal of Consumer Research, v. 9, n. 2, p. 132-140, 1982.

HUE, Jean-François L. M.; Viagem de incentivo uma poderosa ferramenta de marketing. Revista de Administração de Empresas. São Paulo, v. 32, n. 5, 1992.

INNOVARE PESQUISA. Os gastos dos brasileiros no Turismo em 2015 (20-01-2016). Disponível em: <http://www.innovarepesquisa.com.br/blog/os-gastos-dos-brasileirosturismo-em-2015/>. Acesso em: 22/1/2016.

JAFARI, J., AASER, D. Tourism as the subject of doctoral dissertations. Annals of Tourism Research Menomonie, University of Wisconsin Stout, v. 15, p. 407- 429, 2010.

LEAL, S. R. Pesquisa em Turismo no Brasil: uma Revolução Silenciosa? Revista Turismo e Sociedade, v. 4, n. 1, 2011.

MONDO, T. S.; FIATES, G. G. S.; Qualidade de Serviços em Atrativos Turísticos: um estudo da percepção dos turistas de Florianópolis-SC-Brasil. Revista Turismo em Análise, v. 26, n. 1, p. 112-138, 2015.

MAZÓN, A. I. M.; MORALEDA L. F.; SOLÁ, E. F. Tourism for development. In: SOLÁ, E. F.; DA SILVA J. A. M.; JAFARI, J. (Orgs.). Knowledge management in tourism: Policy and governance applications, tourism for development. p. 13-14, 2012.

PORTAL G1. Agenda de Shows - Monster's Tour. Disponível em: <http://g1.globo.com/pr/parana/musica/show/monsters-tour-28-04-2015-pedreira-pauloleminski-ozzy-osbourne-motorhead-judas-priest.html>. Acesso em: 22/1/2016

Agenda de Shows - Country Festival. Disponível em; <http://g1.globo.com/pr/parana/musica/show/country-festival-2015-23-05-2015pedreira-paulo-leminski-luan-santana.html>. Acesso em: 22/1/2016.

Agenda de Shows - Katy Perry. Disponível em: <http://g1.globo.com/pr/parana/musica/show/katy-perry-29-09-2015-pedreira-pauloleminski-katy-perry.html>. Acesso em: 22/1/2016.

FIFA FAN FEST. Disponível em:

<http://g1.globo.com/pr/parana/noticia/2014/07/milhares-de-pessoas-vao-fifa-fan-festde-curitiba-torcer-pelo-brasil.html>. Acesso em: 25/1/2016.

PREFEITURA DE CURITIBA. Portal da Transparência. Disponível em: <http://www.transparencia.curitiba.pr.gov.br/>. Acesso em: 21/1/2016. 
Parques e Bosques de Curitiba - Pedreira Paulo Leminsky. Disponível em: <http://www.curitiba.pr.gov.br/conteudo/parques-e-bosques-parque-das-pedreiras/309>. Acesso em: 21/1/2016.

TEARE, R. E. Best Practices and New Perspectives. In: Service Science and Management, p. 101-106, 1998.

Recebido em: 19-12-2018.

Aprovado em: 14-01-2019.

Versão finalizada para publicação em: 21-01-2019. 


\section{APÊNDICE I}

Guia de perguntas realizadas aos respondentes da pesquisa que visou aferir o atendimento de qualidade em 14/12/2015 - Pedreira Paulo Leminski - Show David Gilmour.
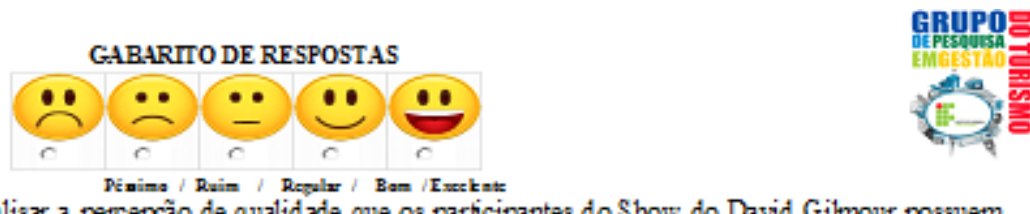

Esta pesquisa tem como objetivo analisar a percepgão de qualidade que os participantes do Show do David Gilmovr possvem Foram criados indicadores de qualidade e gostariamos que você expressasse sua opinião nes ta pesquisa. Ela levará en torno de 4 mimutos. O intvito é que possamos identificar pontos de melhoria para que nos próximos eventos aqui na Pedreira, o serviço oferecido tenha melhor qualidade. Se emalgumitemnão tiver resposta, favor continuar a pesquisa sem assinalar nada. Obrigado!

Como rocê aralia a prestação de informaçóes na entrada do erento pelo pessoal da organiz ação?

$$
\ddot{6} \ddot{6} \because \ddot{*}
$$

Como r ccê aralia a atencão dispensada da pessoa que lhe atendeu?

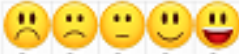

Como r $\propto$ ê aralia 0 atendimento em geral no erento?

$$
\ddot{6} \ddot{\circ} \because \ddot{\theta}
$$

Como rocê arralia a coufiança depositada no pessoal que the atendeu?

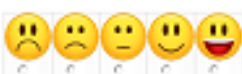

Como rocê ar alia o conhecimento técuico do pessoal que trabalha no etento?

$$
\ddot{0} \ddot{0} \because \ddot{*}
$$

Como rocê aralia a localização, ragas de estacionamento e facilidades de acesso (vias, transporte público, etc) no evento?

$$
\ddot{3} \ddot{\circ} \because \ddot{*}
$$

Como rocê aralia a acessibilidade para pessoas com deficiência no eveuto (rampas, calçadas rebair adas, chão simaliz ado, LIBRAS)?

$$
\ddot{6} \ddot{\circ} \because \ddot{0}
$$

Como r cô aralia a disponibilidade, acesso e limpez a dos banheiros?

$$
\ddot{6} \ddot{\theta} \ddot{\theta} \ddot{\theta}
$$

Como rocê aralia a questão de filas no evento (bares, banheiros outros)?

$$
\ddot{0} \ddot{0} \because \ddot{\theta}
$$

Como rocê aralia o horário de funcionamento do ev ento?

$$
\ddot{6} \ddot{\circ} \ddot{\ddots} \ddot{\theta}
$$

Como r ccê aralia o some a acústica no ev eut 0 ?

$$
\ddot{6} \ddot{\theta} \ddot{\ddots} \ddot{\theta}
$$

Como r œcê aralia as questóes de couforto e 0 ambiente no evento?

$$
\because \ddot{\sigma} \because \because \ddot{*}
$$

Como rocê aralia o seu nírel de aprendi ado com oer ento?

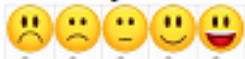

Como r cce aralia o seu nível de diversão no evento?

$$
\ddot{6} \ddot{\bullet} \because \ddot{0}
$$

Como r ocê aralia a estética do erento, a belez a? $\ddot{6} \ddot{\theta} \ddot{\bullet} \ddot{\theta}$
Como rocê axalia o nível de fuga de rotima diária que tere ao participar do evento?

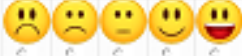

Como rocê aralia a segurança percebida noer ento?

$$
\ddot{0} \ddot{0} \ddot{\sim} \ddot{v}
$$

Como rocê aralia os núveis de preços cobrados para consumo de produtose servicos durante o evento?

$$
\ddot{0} \ddot{\sim} \ddot{\sim} \ddot{0}
$$

Como rocê aralia as coudicónes climáticas para o evento?

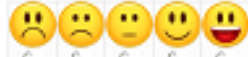

Como rocê aralia a infra zestr ut ư a do erent o?

$$
\ddot{6} \because \ddot{*} \ddot{0}
$$

Como rocê aralia a simaliz ação no ev ento?

$$
\ddot{6} \ddot{\theta} \because \ddot{0}
$$

Como voê avalia a oferta de tecuologia (tótens informativos, wifi etc) no evento?

$$
\because \ddot{0} \because \ddot{*}
$$

Como rocê aralia a limper a no ev ento?

$$
\ddot{6} \because \ddot{0} \ddot{0}
$$

Como rocê aralia a variedade de atividades oferecidas no evento?

$$
\text { ㅂ. } \because \ddot{*} \ddot{\theta}
$$

Como rocê aralia a quantidade de pessoas no eteuto? (Pergunta relatir a à lotação e muito morimento).

$$
\ddot{0} \ddot{0} \ddot{0} \ddot{\theta}
$$

Onde rocê mora (cidade)?:

Gênero:

? Feninino ? Maculino

Qual a sua idade?

Qual seu estado civil?

?Solteiro ? Divorciado

? Casado ? Viưvo

Qual a sua faix a de renda mensal?

? AtE RS724,00

? de RS 725,00 a RS 144800

$?$ de RS 1449,00 a RS 2896,00

$?$ deRS 2897,00 a R5 4344,00

? de RS 4, 345,00 a RS 5792,00

? de RS 5 , 792,00 a RS 7.240,00

? acima de R\$ 7241,00

Qual o seu grau de escolaridade?

$?$ Fundamental ?Médio

? Superio $\quad$ ? Pós-Graduą̧âo 


\section{APÊNDICE II}

Respostas compiladas ao questionário TOURQUAL aplicado em 14/12/2015 na Pedreira Paulo Leminski - Show David Gilmour.

\begin{tabular}{|c|c|c|c|c|c|}
\hline PERGUNTAS & $\begin{array}{l}\text { PÉS- } \\
\text { SIMO } \\
\end{array}$ & RUIM & $\begin{array}{c}\text { RE- } \\
\text { GULAR }\end{array}$ & $\mathrm{BOM}$ & $\begin{array}{l}\text { EXCE- } \\
\text { LENTE }\end{array}$ \\
\hline $\begin{array}{l}\text { Como você avalia a prestação de informações na entrada do evento } \\
\text { pelo pessoal da organização? }\end{array}$ & 1 & 2 & 2 & 52 & 293 \\
\hline Como você avalia a atenção dispensada da pessoa que lhe atendeu? & 0 & 0 & 6 & 85 & 259 \\
\hline Como você avalia o atendimento em geral no evento? & 8 & 15 & 15 & 80 & 232 \\
\hline $\begin{array}{l}\text { Como você avalia a confiança depositada no pessoal que lhe } \\
\text { atendeu? }\end{array}$ & 5 & 10 & 10 & 79 & 246 \\
\hline $\begin{array}{l}\text { Como você avalia o conhecimento técnico do pessoal que trabalha } \\
\text { no evento? }\end{array}$ & 0 & 5 & 9 & 78 & 258 \\
\hline $\begin{array}{l}\text { Como você avalia a localização, vagas de estacionamento e } \\
\text { facilidades de acesso (vias, transporte público, etc.) no evento? }\end{array}$ & 65 & 120 & 12 & 50 & 103 \\
\hline $\begin{array}{l}\text { Como você avalia a acessibilidade para pessoas com deficiência no } \\
\text { evento (rampas, calçadas rebaixadas, chão sinalizado, LIBRAS)? }\end{array}$ & 3 & 10 & 60 & 71 & 144 \\
\hline $\begin{array}{l}\text { Como você avalia a disponibilidade, acesso e limpeza dos } \\
\text { banheiros? }\end{array}$ & 149 & 79 & 48 & 23 & 51 \\
\hline $\begin{array}{l}\text { Como você avalia a questão de filas no evento (bares, banheiros, } \\
\text { outros)? }\end{array}$ & 198 & 79 & 43 & 18 & 12 \\
\hline Como você avalia o horário de funcionamento do evento? & 15 & 10 & 12 & 150 & 163 \\
\hline Como você avalia o som e a acústica no evento? & 2 & 5 & 5 & 180 & 158 \\
\hline Como você avalia as questões de conforto e o ambiente no evento? & 48 & 62 & 98 & 83 & 59 \\
\hline Como você avalia o seu nível de aprendizado com o evento? & 2 & 2 & 50 & 121 & 175 \\
\hline Como você avalia o seu nível de diversão no evento? & 2 & 3 & 5 & 159 & 181 \\
\hline Como você avalia a estética do evento, a beleza? & 95 & 82 & 52 & 75 & 46 \\
\hline $\begin{array}{l}\text { Como você avalia o nível de fuga de rotina diária que teve ao } \\
\text { participar do evento? }\end{array}$ & 2 & 3 & 4 & 89 & 252 \\
\hline Como você avalia a segurança percebida no evento? & 78 & 85 & 59 & 63 & 65 \\
\hline $\begin{array}{l}\text { Como você avalia os níveis de preços cobrados para consumo de } \\
\text { produtos e serviços durante o evento? }\end{array}$ & 125 & 86 & 52 & 61 & 26 \\
\hline Como você avalia as condições climáticas para o evento? & 5 & 8 & 62 & 80 & 195 \\
\hline Como você avalia a infraestrutura do evento? & 50 & 61 & 93 & 81 & 65 \\
\hline Como você avalia a sinalização no evento? & 90 & 79 & 48 & 72 & 61 \\
\hline $\begin{array}{l}\text { Como você avalia a oferta de tecnologia (tótens informativos, wifi, } \\
\text { etc.) no evento? }\end{array}$ & 89 & 75 & 45 & 65 & 76 \\
\hline Como você avalia a limpeza no evento? & 138 & 65 & 58 & 21 & 68 \\
\hline Como você avalia a variedade de atividades oferecidas no evento? & 8 & 5 & 6 & 149 & 182 \\
\hline $\begin{array}{l}\text { Como você avalia a quantidade de pessoas no evento? (Pergunta } \\
\text { relativa à lotação e muito movimento). }\end{array}$ & 218 & 95 & 8 & 8 & 21 \\
\hline
\end{tabular}

